\title{
Large outbreak of isoniazid-monoresistant tuberculosis in London, 1995 to 2006: case-control study and
}

\section{recommendations}

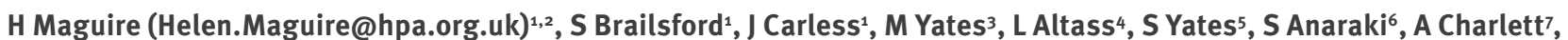

S Lozewicz ${ }^{8}$, M Lipman', G Bothamley ${ }^{10}$

1. Health Protection Agency, London Region Epidemiology Unit, London, United Kingdom

2. St George's Hospital Medical School, London, United Kingdom

3. Health Protection Agency Mycobacterium Reference Unit, Barts and the London School of Medicine and Dentistry, London, United Kingdom

4. North Central London TB Network, Haringey Teaching Primary Care Trust and National Health Service London, London, United Kingdom

5. Her Majesty's Prison Pentonville, London, United Kingdom

6. Health Protection Agency, North East and Central Health Protection Unit, London, United Kingdom

7. Health Protection Agency, Centre for Infections, London, United Kingdom

8. North Middlesex University Hospital, London, United Kingdom

9. Royal Free University Hospital, London, United Kingdom

10. Homerton University Hospital, London, United Kingdom

Citation style for this article:

Maguire H, Brailsford S, Carless J, Yates M, Altass L, Yates S, Anaraki S, Charlett A, Lozewicz S, Lipman M, Bothamley G. Large outbreak of isoniazid-monoresistant tuberculosis in London, 1995 to 2006: case-control study and recommendations. Euro Surveill. 2011;16(13):pii=19830. Available online: http://www.

eurosurveillance.org/ViewArticle.aspx?Articleld $=19830$

Article published on 31 March 2011

We conducted a case-control study to examine risk factors for isoniazid-monoresistant Mycobacterium tuberculosis in an ongoing outbreak in London. Cases were defined as individuals with an isoniazid-monoresistant strain diagnosed from 1995 to the third quarter of $\mathbf{2 0 0 6}$ with an indistinguishable restriction fragment length polymorphism (RFLP) or mycobacterial interspersed repetitive unit (MIRU)-variable number tandem repeats (VNTR) pattern who were resident in or had epidemiological links with London. Controls were all other individuals reported with tuberculosis to the Health Protection Agency London regional epidemiology unit or the HPA London TB Register during 2000 to 2005 . Of 293 cases, 153 (52\%) were sputum smearpositive compared with $3,266(18 \%)$ of controls. Cases were more likely to be young adults (aged between 15 and 34 years), born in the United Kingdom (OR: 2.4; 95\% Cl: $1.7-3.4$ ) and of white (OR: 2.9 ; $95 \% \mathrm{Cl}: 1.8-$ 4.8) or black Caribbean (OR: $12.5 ; 95 \% \mathrm{Cl}: 7.7-20.4$ ) ethnicity, a prisoner at the time of diagnosis (OR: 20.2; 95\% Cl: 6.7-60.6), unemployed (OR: 4.1; 95\% Cl: 3.05.6), or a drug dealer or sex worker (OR: $187.1 ; 95 \% \mathrm{Cl}$ : 28.4-1,232.3). A total of $113(39 \%)$ of cases used drugs and $54(18 \%)$ were homeless. Completion of treatment gradually improved in cases from $55 \%$ among those diagnosed up to the end of 2002 compared with $65 \%$ by the end of 2006. Treatment completion increased from $79 \%$ to $83 \%$ in controls from 2000 to 2005 . There are complex social challenges facing many cases in this outbreak that need to be addressed if medical interventions are to be successful.

\section{Introduction}

The incidence of active tuberculosis (TB) increased in London from 20 per 100,000 population in 1987 to
44 per 100,000 in 2006 [1]. TB in London is concentrated in certain geographical areas and in specific subgroups of the population. During 2000 to 2006, TB rates were consistently higher in north London, among people born outside the United Kingdom (UK) and in those aged 20-29 years [2,3]. The Health Protection Agency (HPA) Mycobacterium Reference Unit in London provides a service for the National Health Service (NHS) in London and the rest of south-east England, confirming the identity of TB isolates and determining drug sensitivities. The proportion of Mycobacterium tuberculosis strains in London that were isoniazid resistant was relatively stable at $8-9 \%$ during 2000 to 2006 [2]. There are over 30 TB clinics in London, which are widely distributed across the city, with reasonable access to them by public or other transport. The 2001 census showed that there were 7.2 million residents in London, living in 31 different boroughs across five areas or sectors (three in the north and two in the south) [4]. Within each sector, levels of deprivation and overcrowding vary and inner London areas are usually more deprived. Overall $30 \%$ of the population were of non-white ethnicity in 2001 [4].

An outbreak of isoniazid-monoresistant TB was first identified in north London in 2000 when microbiologists at a local hospital noted an increase in isoniazid-monoresistant $M$. tuberculosis infections in young men [5]. When strain typing was carried out retrospectively of isoniazid-monoresistant strains from 1995 from that hospital and three neighbouring hospitals carried out at the HPA Mycobacterium Reference Unit using restriction fragment length polymorphism (RFLP) - 11 individuals with strains with indistinguishable 
RFLP patterns were identified. As a result of this, a London-wide Incident Control Committee was established. It was agreed that the HPA Mycobacterium Reference Unit would type isoniazid-monoresistant M. tuberculosis strains from across London prospectively and retrospectively to 1999 (the most recent strains that were then available). Control measures recommended by the Committee, which were outlined in a comprehensive report in 2004 [6], together with progress achieved at the time of this review, are described in Table 1.

There were some service improvements across the city by the end of 2006, including a reported increase in the number of TB nurses and outreach (community-based) initiatives. In addition, since 2002 all TB clinics have been using the HPA London TB Register, a web-based electronic case management and surveillance system. It was developed and has been maintained by the HPA, in collaboration with clinical staff in the city.
The Incident Control Committee also recommended directly observed treatment (DOT) for all cases, following either one of two regimens at the discretion of the clinician (Box).

In this paper we provide results of a case-control study that aimed to determine the risk factors associated with becoming infected with the outbreak isoniazidmonoresistant $M$. tuberculosis strain. We also report on treatment outcome of the cases and describe the particular challenges encountered in implementing the recommended control measures.

\section{Methods}

Microbiological methods

Microbiological methods included typing of isoniazidmonoresistant $M$. tuberculosis isolates at the HPA Mycobacterium Reference Unit. Other Mycobacterium reference units in England were asked to send isoni-

\section{TABLE 1}

Incident Control Committee recommendations, outcomes and actions, isoniazid-monoresistant tuberculosis outbreak, north London, 1995-2006

\begin{tabular}{|c|c|c|}
\hline Issue & Recommendations made in $2002-2004^{a}$ & Outcomes and actions by the end of 2006 \\
\hline Interagency working & $\begin{array}{l}\text { Awareness of TB should be raised in at-risk groups and } \\
\text { professionals who work with them to encourage early } \\
\text { presentation and diagnosis of TB. }\end{array}$ & $\begin{array}{l}\text { Information about the outbreak advising them to have } \\
\text { a low threshold of suspicion of TB was provided to } \\
\text { a range of healthcare and social care professionals, } \\
\text { including those working in drug and alcohol services. }\end{array}$ \\
\hline Identification of cases & $\begin{array}{l}\text { All TB cases in London should be confirmed by } \\
\text { microbiological culture so that drug-sensitivity testing } \\
\text { can be done and molecular typing carried out for those } \\
\text { isoniazid monoresistant. }\end{array}$ & Rate of identification and typing of strains improved. \\
\hline Patients lost to follow-up & $\begin{array}{l}\text { There should be a case-management approach, } \\
\text { including directly observed therapy (DOT), social } \\
\text { support and outreach (community-based health } \\
\text { services including home visits). } \\
\text { Incentives should be used, e.g. providing travel } \\
\text { vouchers or paying travel costs. }\end{array}$ & $\begin{array}{l}\text { Many cases have been non-adherent despite support } \\
\text { and follow-up. } \\
\text { Patients have multiple social problems and health is } \\
\text { not always a high priority for them. } \\
\text { Patients often need cash to pay for travel to the clinic. } \\
\text { Incentives have been used successfully in some } \\
\text { instances. }\end{array}$ \\
\hline Availability of treatment & $\begin{array}{l}\text { All TB therapy should be available free of charge. } \\
\text { Outreach services should be developed. }\end{array}$ & $\begin{array}{l}\text { Good progress made with free treatment but outreach } \\
\text { (home visit) services could be better. }\end{array}$ \\
\hline Contact tracing & $\begin{array}{l}\text { Enhanced contact tracing (to include social and } \\
\text { work contacts) should be undertaken for all cases } \\
\text { particularly for any susceptible contacts (e.g. children, } \\
\text { immunosuppressed patients, injecting drug users). } \\
\text { Contacts of outbreak cases should be screened again } \\
\text { after six months, and only discharged after two clear } \\
\text { screens. }\end{array}$ & $\begin{array}{l}\text { Many patients were reluctant to give names of } \\
\text { contacts or do not know the names of their contacts. } \\
\text { Contacts of drug users often did not attend for } \\
\text { screening. }\end{array}$ \\
\hline $\begin{array}{l}\text { Cases with history of } \\
\text { imprisonment }\end{array}$ & $\begin{array}{l}\text { Better liaison between prison services and health } \\
\text { services is necessary. }\end{array}$ & $\begin{array}{l}\text { Remand prisoners were still being released without } \\
\text { contacting health services. } \\
\begin{array}{l}\text { A specialist nurse was appointed at a London prison } \\
\text { where several cases had been inmates. }\end{array} \\
\text { A mobile digital TB X-ray unit has been used to detect } \\
\text { cases in London prisons since } 2005 \text {. }\end{array}$ \\
\hline $\begin{array}{l}\text { Lack of isolation facilities } \\
\text { in north London hospitals }\end{array}$ & $\begin{array}{l}\text { More isolation facilities should be accessible in } \\
\text { London. Awareness of TB should be raised in hospital } \\
\text { accident and emergency departments to ensure } \\
\text { suspected pulmonary TB cases are isolated on } \\
\text { admission. }\end{array}$ & $\begin{array}{l}\text { Awareness raising in accident and emergency } \\
\text { departments and National Health Service trusts was } \\
\text { carried out. }\end{array}$ \\
\hline
\end{tabular}


azid-monoresistant strains to London for typing if the patient had an epidemiological link with London.

Strains from 1999 available at the HPA Mycobacterium Reference Unit in London were retrospectively typed. The typing techniques used were restriction length fragment polymorphism (RFLP) or, since 2006, mycobacterial interspersed repetitive sequence (MIRU)variable number tandem repeat (VNTR) [7].

\section{Epidemiological methods}

\section{Case definition}

A case was defined as an individual with an isoniazidmonoresistant $M$. tuberculosis strain diagnosed from 1995 to the third quarter of 2006 with an indistinguishable RFLP or MIRU-VNTR pattern who was resident in or had an epidemiological link with London [5].

Control group

Cases in the outbreak $(n=293)$ were compared in a case-control study with a control group of all other

\section{Box}

Recommended treatment options for isoniazidmonoresistant tuberculosis, north London outbreak, 1995-2006

Option 1

Pyrazinamide for the first two months

Moxifloxacin for the first four months

Rifampicin for nine months

Ethambutol for nine months

Option 2

Pyrazinamide for the first two months

Rifampicin for 12 months

Ethambutol for 12 months individuals with TB reported during 2000 to 2001 to the HPA London regional epidemiology unit as part of routine surveillance on a paper-based questionnaire and those reported during 2002 to 2005 electronically by clinicians to the HPA London TB Register. Thus controls were chosen for the time frame for which complete data were readily available $(2000-2005)(n=17,747)$. Although cases had been diagnosed in 1995, there had been few between 1995 and 1999. National surveillance of TB was introduced in 1999, but the data available that year were incomplete and there had been no routine surveillance before then. The controls included those clinically diagnosed by a physician and started on TB treatment as well as others who had culture-confirmed TB. We did not match the cases and controls or restrict the comparison to culture-confirmed controls as we did not wish them to be selected on the basis of similarity in respect of certain characteristics of interest, such as pulmonary disease or sputum smear status, for example.

\section{Data collection and analysis}

A paper-based questionnaire specific for the outbreak was completed retrospectively by TB clinic nurses, once the patient was known to have the outbreak strain, providing details of factors potentially relating to transmission of $M$. tuberculosis, e.g. drug and alcohol use or dependence, imprisonment and any common venues cases may have frequented. The nurses also enquired whether the patient had received DOT, which had been recommended for cases. Interpretation of the meaning and implementation of DOT in practice varied across London. It included the use of dosette boxes, pill counts, urine testing for the presence of anti-tuberculosis drugs or family members acting as supervisors without necessarily directly observing the taking

\section{FIGURE}

Cases of isoniazid-monoresistant tuberculosis by quarter of diagnosis or report, north London outbreak, 1995 to third quarter $2006(n=293)$

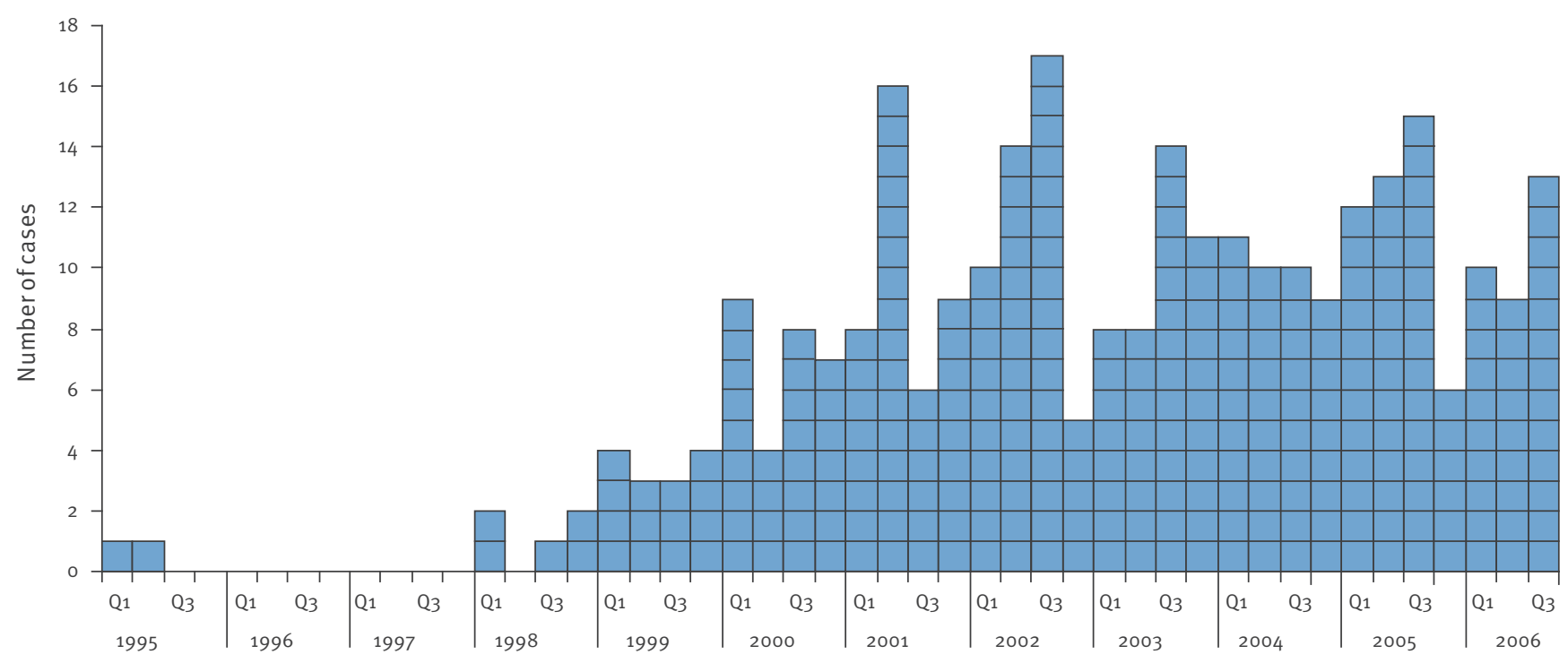

Year and quarter 
TABLE 2

Univariable analysis of association between risk factors and being a case, isoniazid-monoresistant tuberculosis outbreak, north London, 1995 to third quarter 2006

\begin{tabular}{|c|c|c|c|c|c|c|c|}
\hline \multirow[t]{2}{*}{ Variable } & \multicolumn{2}{|c|}{$\begin{array}{c}\text { Cases } 2000 \text { to third } \\
\text { quarter } 2006 \\
n=293\end{array}$} & \multicolumn{2}{|c|}{$\begin{array}{c}\text { Controls } 2000-2005 \\
n=17,747^{\mathrm{a}}\end{array}$} & \multirow[t]{2}{*}{ Odds ratio } & \multirow[t]{2}{*}{$95 \% \mathrm{Cl}$} & \multirow[t]{2}{*}{$P$ value } \\
\hline & $n$ & $\%$ & $\mathrm{n}$ & $\%$ & & & \\
\hline \multicolumn{8}{|l|}{ Place of residence } \\
\hline North-east London & 89 & 30.4 & 4,421 & 24.9 & Reference & - & - \\
\hline South-east London & 15 & 5.1 & 2,670 & 15.0 & 0.28 & $0.15-0.49$ & $<0.0001$ \\
\hline South-west London & 1 & 0.3 & 1,786 & 10.1 & 0.03 & $<0.01-0.2$ & $<0.0001$ \\
\hline North-west London & 11 & 3.8 & 5,362 & 30.2 & 0.10 & $0.05-0.19$ & $<0.0001$ \\
\hline North-central London & 136 & 46.4 & 3,501 & 19.7 & 1.93 & $1.46-2.56$ & $<0.0001$ \\
\hline Outside London & 41 & 14.0 & 0 & 0 & $\mathrm{NE}$ & NE & NE \\
\hline Unknown & 0 & 0 & 7 & 0.04 & $\mathrm{NE}$ & $\mathrm{NE}$ & $\mathrm{NE}$ \\
\hline \multicolumn{8}{|l|}{ Sex } \\
\hline Male & 206 & 70.3 & 9,753 & 54.9 & 1.96 & $1.51-2.55$ & $<0.0001$ \\
\hline Female & 86 & 29.3 & 7,959 & 44.9 & Reference & - & - \\
\hline Unknown & 1 & 0.3 & 28 & 0.15 & NE & $\mathrm{NE}$ & $\mathrm{NE}$ \\
\hline \multicolumn{8}{|l|}{ Age (years) } \\
\hline $0-14$ & 5 & 1.7 & 1,035 & 5.8 & 0.28 & $0.08-0.70$ & $<0.0001$ \\
\hline $15-24$ & 53 & 18.1 & 3,109 & 17.5 & Reference & - & - \\
\hline $25-34$ & 91 & 31.1 & 5,363 & 30.2 & 1.00 & $0.70-1.4$ & 0.97 \\
\hline $35-44$ & 83 & 28.3 & 3,184 & 17.9 & 1.53 & $1.07-2.21$ & 0.02 \\
\hline $45-64$ & 47 & 16.0 & 3,116 & 17.6 & 0.88 & $0.58-1.34$ & 0.54 \\
\hline$\geq 65$ & 14 & 4.8 & 1,902 & 10.7 & 0.43 & $0.22-0.79$ & 0.004 \\
\hline Unknown & 0 & 0 & 31 & 0.17 & $\mathrm{NE}$ & $\mathrm{NE}$ & NE \\
\hline \multicolumn{8}{|l|}{ Ethnicity } \\
\hline Black African & 43 & 14.7 & 5,617 & 31.7 & Reference & - & - \\
\hline Black Caribbean & 85 & 29.0 & 605 & 3.4 & 18.35 & $12.4-27.3$ & $<0.0001$ \\
\hline Black other & 8 & 2.7 & 264 & 1.5 & 3.96 & $1.6-8.6$ & 0.0001 \\
\hline White & 99 & 33.8 & 2,434 & 13.8 & 5.31 & $3.7-7.8$ & $<0.0001$ \\
\hline Indian subcontinent & 15 & 5.1 & 5,691 & 32.1 & 0.34 & $0.18-0.63$ & 0.0002 \\
\hline Chinese & 1 & 0.3 & 251 & 1.4 & 0.52 & $0.13-3.09$ & 0.51 \\
\hline Other & 18 & 6.1 & 2,282 & 12.9 & 1.03 & $0.56-1.83$ & 0.91 \\
\hline Unknown & 24 & 8.2 & 596 & 3.3 & $\mathrm{NE}$ & NE & $\mathrm{NE}$ \\
\hline \multicolumn{8}{|l|}{ Country of birth } \\
\hline Abroad & 112 & 38.2 & 12,953 & 73.1 & Reference & - & - \\
\hline United Kingdom & 153 & 52.2 & 2,930 & 16.5 & 6.03 & $4.68-7.80$ & $<0.0001$ \\
\hline Unknown & 28 & 9.6 & 1857 & 10.5 & $\mathrm{NE}$ & NE & $\mathrm{NE}$ \\
\hline \multicolumn{8}{|l|}{ Employment status } \\
\hline Prisoner & 13 & 4.4 & 26 & 0.1 & 52.62 & $24.12-109.1$ & $<0.0001$ \\
\hline Healthcare & 9 & 3.1 & 523 & 2.9 & 1.81 & $0.8-3.59$ & 0.08 \\
\hline Unemployed & 120 & 41.0 & 2,095 & 11.8 & 6.03 & $4.65-7.89$ & $<0.0001$ \\
\hline Asylum seeker/refugee & 2 & 0.7 & 52 & 0.3 & 4.05 & $0.47-15.7$ & 0.037 \\
\hline Drug dealer/sex worker & 7 & 2.4 & 3 & 0.02 & 245.55 & $54.89-1480.8$ & $<0.0001$ \\
\hline Educational setting & 18 & 6.1 & 2,269 & 12.8 & 0.84 & $0.48-1.38$ & 0.48 \\
\hline Retired & 10 & 3.4 & 759 & 4.3 & 1.39 & $0.64-2.66$ & 0.32 \\
\hline Other & 114 & 38.9 & 11,997 & 67.6 & Reference & - & - \\
\hline Unknown & 0 & 0 & 16 & 0.1 & NE & $\mathrm{NE}$ & $\mathrm{NE}$ \\
\hline \multicolumn{8}{|l|}{ Pulmonary disease } \\
\hline No & 40 & 13.7 & 8,531 & 48.1 & Reference & - & - \\
\hline Yes & 253 & 86.3 & 9,193 & 51.8 & 5.87 & $4.20-8.40$ & $<0.0001$ \\
\hline Unknown & 0 & 0 & 16 & 0.1 & $\mathrm{NE}$ & NE & NE \\
\hline \multicolumn{8}{|l|}{ Sputum smear status } \\
\hline Negative & 79 & 27.0 & 4,138 & 23.3 & Reference & - & - \\
\hline Positive & 153 & 52.2 & 3,266 & 18.4 & 2.45 & $1.85-3.27$ & $<0.0001$ \\
\hline Unknown & 51 & 17.4 & 4,365 & 24.6 & $\mathrm{NE}$ & NE & $\mathrm{NE}$ \\
\hline Not tested & 10 & 3.4 & 5,971 & 33.7 & $\mathrm{NE}$ & $\mathrm{NE}$ & $\mathrm{NE}$ \\
\hline
\end{tabular}

NE: not estimated.

${ }^{a}$ For all variables except place of residence, only controls with a known place of residence were included $(n=17,740)$. 
of medication. Nurses obtained the relevant information in interviews with cases and supplementary data were obtained from medical records. Investigations were also carried out by a nurse at a London prison where many early cases were linked. This was part of an ongoing outbreak investigation and ethical approval was not sought. Patients, as per normal clinical practice, were able to refuse to answer questions if they wished.

Once outbreak questionnaires were returned, the information was entered into a database and aligned with data from routine surveillance and the HPA London TB Register, to ensure consistency and completeness. Since 2002, questionnaire data were supplemented by, aligned with and cross-checked against data retrieved directly from the Register. For those cases who did not receive DOT, we telephoned the case manager at the clinic to enquire about the reasons for this. We asked whether the case was homeless, for example, or had been initially thought likely to have poor adherence to treatment or had had a history of poor adherence in any previous episode of TB.

Odds ratios (ORs) were estimated for cases $(n=293)$ and controls $(n=17,747)$ for place of residence. For the following variables, only controls with a known place of residence were included $(n=17,740)$ : sex, age, site of disease, sputum smear status, type of employment, ethnicity and country of birth. Logistic regression was used to obtain unadjusted odds ratios for each variable. Those variables found to be statistically significant were included in a multivariable analysis using logistic regression to control for confounders. Statistical analysis was carried out using Stata version 10.

Outcome after 12 months of treatment was also examined for cases resident in London (as this information was not available for those resident elsewhere). Reasons for non-completion of the prescribed treatment, recorded in the HPA London TB Register, included death of the patient, moving out of London or overseas, treatment stopped, lost to follow-up or treatment continuing.

\section{Results}

By the end of 2006, 293 people with the same strain of isoniazid-monoresistant TB (cases) were identified, of whom 252 (86\%) were diagnosed in London. By the third quarter of 2006, the incidence of new cases appeared to have levelled at about 10 per quarter, with no evidence of a decline (Figure).

The outbreak remained focused in north London: 136 $(46 \%)$ of the cases were resident in north-central London and $89(30 \%)$ in north-east London. A total of 13 cases $(4.4 \%)$ were prisoners at the time of their diagnosis and two of these were known to have close social links with at least 14 others cases diagnosed before 2003. Another prisoner had close social links with a further four cases who in turn were known contacts of a further eight cases [5]. Social links such as these were frequently observed among cases in north London, but no specific venues, such as hostels or churches, were commonly reported.

\section{Sex, age and sociodemography}

Univariable analysis of the clinical and demographic details of cases and controls are shown in Table 2.

Cases were more likely to reside in north-central or north-east London than any other sector. They were likely to be male (70\% vs $55 \%$; OR 1.96 ; $95 \%$ Cl: $1.51-$ 2.55 ) and be younger than controls ( $28 \%$ vs $18 \%$ aged $35-44$ years: OR: $1.53 ; 95 \% \mathrm{Cl}: 1.07-2.21$ and $5 \%$ vs $11 \%$ aged 65 years or older, OR: $0.43 ; 95 \% \mathrm{Cl}: 0.22-0.79$ ).

A total of 99 (34\%) cases were white and 85 (29\%) black Caribbean: cases were significantly more likely to belong to these ethnic groups. Cases were more likely to be born in the UK than abroad: $153(52 \%)$ of the cases were born in the UK compared with $2,930(17 \%)$ of controls. The predominant countries of birth among cases born abroad were Jamaica $(n=23,21 \%)$, Ireland $(n=15,13 \%)$, Somalia $(n=8,7 \%)$ and Nigeria $(n=6,5 \%)$. A different pattern was observed among controls born abroad, with the majority born in India (17\%), Somalia $(16 \%)$ and Pakistan (7\%).

\section{Employment status}

A total of $120(41 \%)$ of the cases were unemployed at the time of diagnosis compared with $2,095(12 \%)$ of controls (OR: $6.03 ; 95 \% \mathrm{Cl}: 4.6-7.9$ ). Cases were more likely to be a prisoner at the time of diagnosis ( $4.4 \%$ vs $0.1 \%$; OR: $52.6 ; 95 \% \mathrm{Cl}: 24-109)$ and to be a drug dealer or sex worker $(n=7)(2.4 \%$ vs $0.02 \%$; OR: 245 ; $95 \% \mathrm{Cl}: 55-1,480$ ), although the numbers were small.

\section{Other risk factors}

A total of 101 (34\%) cases had a known history of prison detention at some point in the past. There were 113 (39\%) with a history of recreational drug use: injecting drug use was reported by $15(5 \%)$ cases, $24(8 \%)$ stated that they used crack cocaine and the remainder reported the use of drugs such as cannabis. Of the cases, $54(18 \%)$ were known to be homeless at the time of diagnosis, while $20(7 \%)$ had a history of alcohol dependence. Data on these risk factors - prior prison detention, as distinct from being a prisoner at the time of diagnosis, homelessness and recreational drug use - were not routinely collected in the HPA London TB Register and therefore could not be compared among cases and controls. However, we describe their frequency among cases here and compare them with expected frequencies in the London population on the basis of published reports.

\section{Site of disease and sputum smear status}

There were $253(86 \%)$ cases with pulmonary TB compared with 9,193 (52\%) of controls (OR: $5.9 ; 95 \% \mathrm{Cl}$ : 4.2-8.4). Cases were more likely to be sputum smear- 
positive at the first clinic visit compared with controls ( $52 \%$ vs $18 \%$; OR: $2.4 ; 95 \% \mathrm{Cl}: 1.9-3.3$ ).

\section{Multivariable analysis}

In a multivariable analysis, cases were significantly more likely to live in north-central London, be young (aged 15-34 years), UK born (OR: $2.4 ; 95 \% \mathrm{Cl}: 1.7-$ 3.4) and of white (OR: $2.9 ; 95 \% \mathrm{Cl}: 1.8-4.8$ ) or black Caribbean (OR: $12.5 ; 95 \%$ Cl: 7.7-20.4) ethnicity, a current prisoner (OR: 20.2; 95\% Cl: 6.7-60.6), unemployed (OR: $4.1 ; 95 \% \mathrm{Cl}: 3.0-5.6)$ or a drug dealer or sex worker (OR: 187.1; 95\% Cl: 28.4-1,232.3) compared with controls (Table 3 ).

\section{Multidrug-resistant tuberculosis}

and previous treatment

Eight (3\%) of the 293 cases had multidrug-resistant (MDR) TB, by definition resistant to rifampicin and

\section{TABLE 3}

Multivariable analysis of association between risk factors and being a case, isoniazid-monoresistant tuberculosis outbreak, north London, 1995 to third quarter $2006(\mathrm{n}=293)$

\begin{tabular}{|c|c|c|c|}
\hline Variable & Odds ratio & $95 \% \mathrm{Cl}$ & Pvalue ${ }^{a}$ \\
\hline \multicolumn{4}{|l|}{ Place of residence } \\
\hline North-east London & Reference & - & - \\
\hline South-east London & 0.23 & $0.13-0.40$ & 0.002 \\
\hline South-west London & 0.04 & $0.13-0.40$ & $<0.001$ \\
\hline North-west London & 0.17 & $0.09-0.32$ & $<0.001$ \\
\hline North-central London & 1.67 & $1.22-2.29$ & 0.001 \\
\hline \multicolumn{4}{|l|}{ Sex } \\
\hline Male & 1.34 & $0.98-1.83$ & 0.07 \\
\hline Female & Reference & - & - \\
\hline \multicolumn{4}{|l|}{ Age (years) } \\
\hline $0-14$ & 0.30 & $0.09-1.01$ & 0.05 \\
\hline $15-24$ & Reference & - & - \\
\hline $25-34$ & 0.79 & $0.52-1.20$ & 0.27 \\
\hline $35-44$ & 0.64 & $0.41-1.00$ & 0.05 \\
\hline $45-64$ & 0.45 & $0.27-0.74$ & 0.002 \\
\hline$\geq 65$ & 0.23 & $0.10-0.51$ & $<0.001$ \\
\hline \multicolumn{4}{|l|}{ Ethnicity } \\
\hline Black African & Reference & - & - \\
\hline Black Caribbean & 12.52 & $7.69-20.37$ & $<0.001$ \\
\hline Black other & 3.29 & $1.35-8.02$ & 0.009 \\
\hline White & 2.94 & $1.79-4.83$ & $<0.001$ \\
\hline Indian subcontinent & 0.57 & $0.30-1.10$ & 0.092 \\
\hline Chinese & 0.68 & $0.09-5.05$ & 0.703 \\
\hline Other & 1.210 & $0.67-2.19$ & 0.528 \\
\hline \multicolumn{4}{|l|}{ Country of birth } \\
\hline Abroad & Reference & - & - \\
\hline United Kingdom & 2.40 & $1.68-3.43$ & $<0.001$ \\
\hline \multicolumn{4}{|l|}{ Employment status } \\
\hline Prisoner & 20.21 & $6.75-60.56$ & $<0.001$ \\
\hline Healthcare & 1.53 & $0.67-3.51$ & 0.316 \\
\hline Unemployed & 4.09 & $2.97-5.63$ & $<0.001$ \\
\hline Asylum seeker/refugee & 8.09 & $1.02-64.41$ & 0.048 \\
\hline Drug dealer/sex worker & 187.07 & $28.40-1,232.35$ & $<0.001$ \\
\hline Educational setting & 1.22 & $0.67-2.23$ & 0.524 \\
\hline Retired & 1.69 & $0.71-4.06$ & 0.239 \\
\hline Other & Reference & - & - \\
\hline \multicolumn{4}{|l|}{ Pulmonary disease } \\
\hline No & Reference & - & - \\
\hline Yes & 1.52 & $0.98-2.36$ & 0.61 \\
\hline \multicolumn{4}{|l|}{ Sputum smear status } \\
\hline Negative & Reference & - & - \\
\hline Positive & 1.37 & $0.98-1.93$ & 0.067 \\
\hline
\end{tabular}

${ }^{a}$ A p value of $<0.05$ was considered statistically significant. 
isoniazid [8]; three of these were initially resistant to isoniazid alone. Five, including a 15-year-old girl, appear to have become infected in the community with an MDR strain [9].

In addition to the three cases with MDR TB mentioned above, there were 10 cases who had previously been treated for TB. Seven of the 10 had successfully completed treatment for the previous TB episode and had been diagnosed 1, 5, 6, 14, 29 and 32 years previously (the date of the previous TB episode was unknown in one of the seven cases). One further case had been diagnosed seven years previously and had transferred out of London to complete treatment at that time and was then subsequently diagnosed in London with the outbreak strain. One further case diagnosed in 2005 had been treated one year previously and at that time, had not been identified as part of the outbreak. This case had been lost to follow-up. A case who died had apparently been treated for TB previously, but we were unable to confirm the date of treatment.

\section{Directly observed treatment}

By the end of 2006, all but 11 cases had received DOT. Of these 11, four had no documented risk factors at the time of diagnosis (according to the National Institute for Health and Clinical Excellence (NICE) criteria [10]) i.e. homelessness, thought by clinic staff to be likely to have poor adherence to treatment or had a history of poor adherence. Of the remaining seven, six were homeless.

\section{Treatment outcome}

By the end of 2006, of the cases living in London $(n=252), 164(65 \%)$ had reportedly completed treatment (either a nine- or 12-month regimen), 35 (14\%) were described as continuing treatment and 24 (10\%) were lost to follow-up, 11 had died and six had stopped treatment (Table 4).

Completion of treatment among cases gradually improved over time from $55 \%$ among those diagnosed up to the end of 2002 to $65 \%$ in 2006 , compared with

\section{TABLE 4}

Treatment outcome after 12 months among London cases, isoniazid-monoresistant tuberculosis outbreak, north London, 1995-2006 (n=252)

\begin{tabular}{|l|r|r|}
\hline Outcome & $\begin{array}{r}\text { Number of } \\
\text { cases }\end{array}$ & Percentage \\
\hline Treatment completed & 164 & 65.1 \\
\hline Treatment continuing & 35 & 13.9 \\
\hline Lost to follow-up & 24 & 9.5 \\
\hline Died & 11 & 4.4 \\
\hline Stopped treatment & 6 & 2.4 \\
\hline Transferred to another TB service & 5 & 2.0 \\
\hline Refused treatment & 3 & 1.2 \\
\hline Relapsed & 2 & 0.8 \\
\hline Unknown & 2 & 0.8 \\
\hline Total & 252 & 100 \\
\hline
\end{tabular}

$79 \%$ in 2000 to $83 \%$ in 2005 observed among controls. All the cases subsequently lost to follow-up $(n=24)$ were either recreational drug users or were homeless. In an effort to ensure their adherence to treatment, two of the cases were admitted to hospital under a public health section (force of law).

\section{Discussion}

This outbreak of isoniazid-monoresistant TB, first identified in 2000, is ongoing. We have analysed here the early part of the outbreak. In 2000, there were 28 cases (with 21 in the five years before that) and by the third quarter of 2006, there were 293 in total, with no evidence of a decline. By the end of 2010 , the total was just over 400 cases, with some evidence of a decline in the rate of emergence of new cases, to about five per quarter (unpublished data). Information about the outbreak has been presented locally $[11,12]$ : in this paper, we describe the case-control study, to share the lessons learnt. This has been a large and complex outbreak with many demands placed on health services and clinical staff in London as well as the HPA regional epidemiology unit, which has been providing support for data collection, collation and reporting on the outbreak.

Cases were more likely to be born in the UK than controls and were also more likely to be white or Black Caribbean. The proportion born in Jamaica rose considerably since December 2001, when there was just one Jamaican case (of 77 cases, 1.3\%) [5], but by the end of 2006 , there were 61 such cases $(20.8 \%)$. The Irishborn proportion rose modestly from $11 \%$ to $13 \%$. We do not have accurate immigration data for north central London to explore the reasons for this.

Recreational drug use was reported by nearly one in four cases, with $5 \%$ injecting and $8 \%$ using crack cocaine. Although a direct comparison with controls was not possible for these behaviours, previous research into TB in London suggests we might expect $6 \%$ of people to report any 'problem' drug use (recreational drug use, crack cocaine use and injecting drug use). While we observed that $18 \%$ of cases were homeless, we might expect the figure to be $4-12 \%[13,14]$. One third of outbreak cases had a known history of prison detention while up to $18 \%$ of TB cases in London might be expected to ever have been detained in prison $[13,14]$. Such social factors are recognised to play an important role in TB acquisition as well as management in London $[15,16]$.

A high proportion of cases were sputum smear-positive. Adherence to treatment has been poor and thus the degree and duration of infectiousness was likely to have been greater than among other TB cases. As per NICE guidance [10], each TB patient had a named case manager. Some TB clinics have reported successfully using incentives including cash, food, clothes and travel cards to ensure treatment adherence. Research carried out in the United States (US) comparing cash incentives with an alternative to the same value 
showed that more follow-up time was required in the non-cash group. These American studies showed independent predictors of completion were stable housing at the outset of treatment and being male [17].

Outbreak cases often have been reluctant to provide contact details and those identified by drug users were especially unlikely to attend for screening [18]. In the US, a small outbreak of 89 drug-sensitive TB cases among drug users in California [19] was controlled using an outreach community-based approach to deliver preventive treatment to contacts with latent TB. We also used home visits to try and ensure treatment adherence. A digital X-ray screening van was initially introduced in 2005 in London and has been used since then across London among susceptible populations, e.g. prisoners and drug users, to try to engage marginalised people who are unable or do not want to use conventional health services.

There are a number of limitations to our study. We used data collected from London TB surveillance systems and questionnaires completed by TB nurses. Because of the particular interest in the outbreak cases, some information, such as being a prisoner, drug dealer or sex worker at the time of diagnosis, may have been obtained more systematically for cases than for controls and therefore the findings should be interpreted cautiously. There were also very wide confidence intervals for the measure of association for being a drug dealer or sex worker, reflecting the small numbers involved. In addition, the typing strategy has been to type isolates that display isoniazid monoresistance. Universal molecular typing was not being done in London during the study period. We have compared the relative odds of risk factors in cases and controls. The control group included individuals with clinically diagnosed TB as well as culture-confirmed TB, excluding those with the outbreak strain. Some cases may have been misclassified as controls because some individuals diagnosed clinically may have been infected with the outbreak strain but were not culture confirmed. This could lead to bias in estimates of association [20]. A more appropriate control group may be one that reflects the base exposures in the population from which the cases were drawn [21]. Since early 2010, universal strain typing has been introduced across London and it is anticipated that this will allow the full extent of the current outbreak to be better elucidated in the future. Nonetheless, the epidemiology of the outbreak has allowed the Incident Control Committee to develop an understanding of the factors associated and to target their control efforts.

Many lessons in this outbreak are applicable to TB control in general, including the need for DOT for vulnerable patients (as per NICE recommendations) as well as multidisciplinary case conferences to plan treatment and housing and social support for cases who are difficult to treat. With nearly one in 10 outbreak cases lost to follow-up, clearly there is a need to do better.
Education of healthcare professionals and those working in drug and alcohol services about TB in general and this outbreak in particular has been stepped up and a centralised team has been created to find and treat cases that are lost to follow-up. There is also a need for more prompt identification of pulmonary TB cases in London including, for example, in settings such as hospital accident and emergency departments.

We noted that the rapid movement of prisoners between prisons made it very difficult to keep track of prisoners and several recommendations were made for improved TB control in this setting, including reducing the movement of infected prisoners where possible, raising general awareness of TB in prisons and introducing TB screening on entry to prison. Additionally, the use of DOT for all prisoners with TB was recommended, as well as better communication with community teams on the release of any prisoners with TB. The advent of the use of a mobile digital X-ray screening facility in London has resulted in its regular use in prisons and this has been found to be helpful (an evaluation is underway). Support for ex-prisoners with TB is essential and health and social services, including the voluntary sector and criminal justice system, need to work together to ensure that the release of prisoners is properly planned.

We have identified a number of large outbreaks of drug-resistant TB in Europe, including one community outbreak in Sweden, reported in 2011, involving 115 isoniazid-resistant cases over a nine-year period that were characterised by RFLP and spoligotyping [22]. RFLP was also used to identify cases in an outbreak of MDR TB among HIV-infected injecting drug users attending a large HIV unit in central Lisbon, Portugal, in 1995 to 1996 [23]. There were 95 cases of MDR TB and $80 \%$ of the strains were available for typing. These clustered into one of two large clusters. Transmission occurred among HIV-infected injecting drug users exposed to infectious TB cases on open wards in the HIV unit. Although we were not systematically collecting HIV status data on the TB cases in our London outbreak, clinicians reported that among those tested, $12 \%$ were HIV positive (M. Lipman, personal communication, Jun 2005).

We believe that our outbreak is the largest documented outbreak of drug-resistant TB in Europe so far. It has highlighted the need for greatly improved TB services in London and enhanced integration of health and social services. DOT should form part of a wider holistic care package addressing housing and other social needs. The voluntary sector and local authorities, working together with drug and alcohol services, have a key role to play in ensuring that secure housing and supportive care accompany appropriate medical treatment. 


\section{Acknowledgements}

We gratefully acknowledge the help of doctors, nurses and other staff across the city who have provided information and made such great efforts to manage and support the patients in this outbreak.

\section{References}

1. Health Protection Agency (HPA). Tuberculosis in the UK. Annual report on tuberculosis surveillance and control in the UK 2007. London: HPA Centre for Infections; Nov 2007. Available from: http://www.hpa.org.uk/webw/HPAweb\&HPAwebStandard/HPA web_C/1204100459636?p=1158945066450

2. Health Protection Agency (HPA). Tuberculosis in London 2009: Annual report on tuberculosis surveillance in London. London: HPA London Regional Epidemiology Unit; Jan 2011. Available from: http://www.hpa.org.uk/web/HPAwebFile/ HPAweb_C/1294740919741

3. Anderson SR, Maguire H, Carless J. Tuberculosis in London: a decade and a half of no decline. Thorax. 2007;62(2):162-7. Erratum in: Thorax. 2007;62(6):474.

4. Office for National Statistics (ONS). Population by ethnic group, 2001 ward. London: ONS,: 2001. Available from: http:// data.london.gov.uk/datafiles/demographics/ethnic-groupward-2001.xls

5. Ruddy MC, Davies AP, Yates MD, Yates S, Balasegaram S, Drabu Y, et al. Outbreak of isoniazid resistant tuberculosis in north London. Thorax. 2004;59(4):279-85.

6. Davies A, Ruddy M, Neely F, Ruggles R, Maguire H. Outbreak of isoniazid resistant mycobacterium tuberculosis in north London 1999 - 2004. Executive summary report key points and recommendations: London: Health Protection Agency. [Accessed 21 Mar 2011]. Available from: http://www.hpa.org. uk/web/hpawebfile/hpaweb_c/1194947410877

7. van Embden JD, Cave MD, Crawford JT, Dale JW, Eisenach KD, Gicquel B, et al. Strain identification of mycobacterium tuberculosis by DNA fingerprinting: recommendations for a standardized methodology. J Clin Microbiol. 1993;31(2):406-9.

8. Health Protection Agency (HPA). Antimicrobial resistance in England, Wales and Northern Ireland, 2006. London: HPA; 2007. Available from: http://www.hpa.org.uk/web/ HPAwebFile/HPAweb_C/1204100435389

9. Maguire H, Ruddy M, Bothamley G, Patel B, Lipman M, Drobniewski F, et al. Multidrug resistance emerging in North London outbreak. Thorax. 2006;61(6):547-8.

10. National Centre for Health and Clinical Excellence (NICE). Tuberculosis (replaced by CG117). Clinical diagnosis and management of tuberculosis, and measures for its prevention and control. Clinical Guideline 33, Mar 2006. London: NICE. Available from: http://www.nice.org.uk/CGo33

11. Maguire H, Carless J, Mumtaz S, Kinross P. Isoniazid resistant TB outbreak in London. 2000 to 2008. Progress report for TB professionals across London. November 2008. London: Health Protection Agency. Available from: http://www.hpa.org.uk/ web/HPAwebFile/HPAweb_C/1237277187078

12. Maguire H, Forrester S, Adam S on behalf of the London Isoniazid Resistant TB Outbreak Control Committee. Isoniazid resistant TB outbreak in London 2000 to 2006 . Progress report and updated recommendations of the London Outbreak Control Committee. May 2006. London: Health Protection Agency. Available from: http://www.hpa.org.uk/web/HPAwebFile/ HPAweb_C/1194947375784

13. Maguire H, Dale JW, McHugh TD, Butcher PD, Gillespie SH, Costetsos A, et al. Molecular epidemiology of tuberculosis in London 1995-7 showing low rate of active transmission. Thorax. 2002;57(7):617-22.

14. Story A, Murad S, Roberts W, Verheyen M, Hayward AC; London Tuberculosis Nurses Network.Tuberculosis in London: the importance of homelessness, problem drug use and prison. Thorax. 2007;62(8):667-71.

15. Craig GM, Booth H, Story A, Hayward A, Hall J, Goodburn A, et al. The impact of social factors on tuberculosis management. Adv Nurs. 2007;58(5):418-24.

16. Story A, Bothamley G, Hayward A. Crack-cocaine and infectious tuberculosis. Emerg Infect Dis. 2008;14(9):1466-9.

17. Tulsky JP, Hahn JA, Long HL, Chambers DB, Robertson MJ, Chesney MA, et al. Can the poor adhere? Incentives for adherence to TB prevention in homeless adults. Int J Tuberc Lung Dis. 2004;8(1):83-91.
18. Neely F, Maguire H, Le Brun F, Davies A, Gelb D, Yates S. High rate of transmission among contacts in large London outbreak of isoniazid mono-resistant tuberculosis. J Public Health. 2010;32(1):44-51.

19. Malotte CK, Hollingshead IR, Larro M. Incentives vs outreach workers for latent tuberculosis treatment in drug users. Am J Prev Med. 2001;20(2):103-7.

20. Murray M. Sampling bias in the molecular epidemiology of tuberculosis. Emerg Infect Dis. 2002;8(4):363-9.

21. Murray M, Alland D. Methodological problems in the molecular epidemiology of tuberculosis. Am J Epidemiol. 2002;155(6):565-71.

22. Sandegren L, Groenheit R, Koivula T, Ghebremichael S, Advani $A$, Castro E, et al. Genomic stability over 9 years of an isoniazid resistant Mycobacterium tuberculosis outbreak strain in Sweden. PLoS One. 2011;6(1):e16647.

23. Hannan MM, Peres H, Maltez F, Hayward AC, Machado J, Morgado A, et al. Investigation and control of a large outbreak of multi-drug resistant tuberculosis at a central Lisbon hospital. J Hosp Infect. 2001;47(2):91-7. 